\title{
La Responsabilidad Penal del Médico
}

\author{
Por el Dr. JULIO ALTMANN SMYTHE $\left(^{*}\right)$
}

\section{EL EJERCICIO PROFESIONAL}

El ejercicio de las profesiones se halla limitado. Legalmente sólo pueden ejercerlas aquellas personas que ostentan el correspondiente título habilitante y se encuentren premunidas de la respectiva autorización para practicarlas. De esta manera la Sociedad defiende a sus miembros de la deshonestidad y de la ineptitud de quienes pretendan practicarlas valiéndose de la ignorancia y de las necesidades del prójimo, con fines lucrativos.

En verdad, el ejercicio de una profesión es tarea delicada, compleja y vasta. Consiguientemente, para practicarla se requiere de una amplia $y$ profunda formación técnica y ética. Nunca será suficiente la insistencia que se haga para que nuestros centros de estudios universitarios extremen las medidas para que se consiga la formación de profesionales aptos, concientes $\mathrm{y}$ morales.

Conviene poner especial énfasis en la necesidad de que el profesional actúe siempre de acuerdo con elevadas normas éticas. No es bastante, pues, la correcta formación técnica. Como lo ha señalado el recordado Maestro cubano José Agustín Martínez: "La expedición del título académico no es solamente una demostración de la capacidad del diplomado, sino un depósito de la pública confianza, por cuanto se espera que el profesional titulado ha de ejercer una profesión de conformidad con las leyes y de acuerdo con los cánones de la ética profesional". Podríase agregar que la pública confianza puede ser otorgada únicamente a quienes la merezcan. Si alguien es indigno de ella, carece del mérito necesario para ejercer una profesión y, por tanto, su próctica le debe ser suspendida.

Para las personas que reunan los requisitos que la Ley exige, el ejercicio profesional constituye un derecho. Sin embargo, este derecho lleva invívito una serie de obligaciones $y$ de responsabilidades por cuanto la próctica de una profesión invariablemente ha de sujetarse a determinadas reglas de capacidad. de consagración y de moralidad. Si en un profesional faltan estos indispensables requisitos, éste carece de los rasgos que le deben ser peculiares.

(*) Abogado, antiguo Director de Establecimientos Penales en el Ministerio de Justicia, y alto funcionario de las Naciones Unidas. 
Desde el punto de vista legal, todos los profesionales han de responder de las faltas que cometan en la práctica de su profesión. Pero los médicos-cirujanos, en particular, son los que mayores responsabilidades tienen al practicar la ciencia de curar, ya que de su correcto ejercicio dependen los bienes más preciados del ser humano: la salud y la vida.

Es sabido que el médico-cirujano goza de atributos, que no se extien. den $\alpha$ otros profesionales. Está autorizado, por ejemplo, a emplear métodos que pueden causar heridas o mutilaciones a los pacientes, si se producen con fines curativos. Sólo se exige la expresa autorización del paciente o de su representante legal. Algunas legislaciones permiten la intervención quirúrgica en casos de extrema urgencia, sin la indicada autorización. Este eximente se aplica a todo género de tratamientos médico-quirúrgicos, ya sea que se actúe sobre el cuerpo físico o sobre la psiquis del paciente.

El ejercicio de la medicina, pues, exige mayormente no sólo una excelente formación técnica y ética, sino, además, de un gran espíritu de dedicación y de un acertado criterio, por cuanto el título de médico-cirujano ha de significar siempre una plena garantía de que el paciente será sometido a un correcto tratamiento, de acuerdo a los últimos conocimientos alcanzados en el incesante perfeccionamiento del arte de curar.

\section{EL EIFRCICIO DE LA MEDICINA}

La Ciencia Médica ha debido recorrer un largo camino antes de llegar a convertirse en lo que es. El arte de curar en sus comienzos no fué sino una práctica de conocimientos empíricos, mezcla de supersticiones, hechicerías, sugestiones, aplicación de substancias a las que la experiencia había dado propiedades medicinales, etc., etc. Aún en tiempos menos remotos la medicina acusaba conceptos rutinarios e inverosímiles. Valen recordar algunas máximas de la medicina clásica: "similia similibus curantur", usada por los homeópatos, y la empleada por sus opositores, "contraria contrariis curantur". En verdad, la Ciencia Médica propiamente dicha tiene una existencia relativamente corta $\mathrm{y}$. puede decirse, aún se halla en los primeros peldaños de su evolución.

Actualmente, la práctica de la medicina abarca un campo amplísimo. Sin embargo, la principal labor del facultativo consiste en tratar médico-quirúrgicamente al ser humano, esto es, prevenir enfermedades, curar enfermos, salvar vidas $\mathrm{y}$, en muchos casos, hermosearlo físicamente. Justamente, este tratamiento presupone condiciones especiales en el profesional, si se desea éxito.

El exacto significado del tratamiento médico-quirúrgico es bastante lato. No debe extrañar, entonces, que abunden las definiciones de lo que es este tratamiento. Siguiendo a Grispigni, a Jiménez de Asúa y a otros notables tratadistas, podría decirse que el tratamiento médico-quirúrgico consiste en toda intervención en el organismo humano ajeno, ceñida a las reglas indicadas por la Ciencia, con fines de asegurar la salud física o psiquica de una persona, o para mejorar su aspecto estético con el empleo de medios adecuados. Por tanto, tiende a conservar o devolver la salud física 
- psíquica, a salvar vidas humanas o a perfeccionar el aspecto de las personas.

Los errores que cometa el facultativo en el cumplimiento de estas delicadas tareas suelen producir daños invalorables en los seres humanos que las sufran, dada la trascendencia que tienen. Si el tratamiento es aplicado por personas que carezcan de los conocimientos y la habilidad necescrios es casi fatal que los daños se han de producir con peligrosa frecuencia.

Aunque actualmente la medicina ha dejado mucho de su primitivo empirismo y se ha hecho más Ciencia, en el alma popular superviven muchos antiguos conceptos, toda vez que los nuevos conocimientos no han podido todavía eliminar totalmente de la mente del pueblo opiniones sumamente arraigadas, las que, al perdurar, son utilizadas lucrativamente por sujetos faltos de honestidad. Es natural que la Ley defienda la salud y la vida de las personas prohibiendo el "curanderismo", en sus diversas manifestaciones. La represión del "curanderismo" tiene un interés social, por cuanto es indiscutible que la Sociedad está en el deber irrefragable de velar por la salud y por la vida de sus componentes. Es lógico, entonces, que la Ley determine normas que hagan imposible que el tratamiento médicoquirúrgico sea aplicado por personas incapaces $Y$ deshonestas, especialmente por individuos no diplomados.

Aunque es poco frecuente, no faltan médicos que actúen deshonestamente frente $\alpha$ sus pacientes, engañándolos, al hacerles creer que mediante la aplicación de determinados métodos, sólo por ellos conocidos, obtendrán la curación de sus males con absoluta seguridad. La Ley debe reprimir, igualmente, a estos malos profesionales.

Estas infracciones se hallan reprimidas por el artículo 280 del Código Penal, el que a la letra dice: "El que, sin título ni autorización para el ejercicio de un arte de curar o excediéndose los límites de su autorización, anunciare, prescribiere, administrare o aplicare habitualmente medicamentos, aguas, electricidad, hipnotismo o cualquier medio destinado al tratamiento de las enfermedades de las personas, aún a título gratuito, será reprimido con prisión no mayor de un año y multa de tres a noventa días, 0 con una sola de estas penas".

Tratóndose de la defensa de los más preciados bienes del hombre, la sanción no está de acuerdo con la gravedad de las infracciones cometidas. Debiera extremarse la sanción cuando un facultativo, escudado por su título, actúa con falsedad, engañando a los enfermos que fían en él. Tal opinión es unánime entre los mejores penalistas.

En nuestro país el ejercicio ilegal de la medicina constituye una lacra de difícil erradicación. Abundan los "curanderos", esto es, personas que practican el arte de curar sin título habilitante $y$ sin la correspondiente autorización. Sus consultorios funcionan públicamente, por lo general con la complacencia o con la complicidad de muchas autoridades llamadas, justamente, a hacer cumplir la Ley. Las disposiciones del Art. 280 del Código punitivo, no operan pues frecuentemente en la práctica. Es del todo necesario reaccionar frente a tan peligrosa realidad, haciéndose cumplir este precepto legal en forma irrefragable. 


\section{LA "FALTA MEDICA"}

El médico-cirujano ha de responder por las faltas que cometa en la práctica de su profesión, esto es, por las "faltas médicas". Naturalmente. las que carezcan del carácter de "falta médica" propiamente dicha caen dentro del marco legal ordinario, ya sea civil o penal. El presente trabajo no se ha de ocupar de las últimas, sino circunstancialmente. Sólo ha de referirse a las denominadas "faltas médicas" propiamente dichas.

No siempre es sencillo determinar cuándo se ha cometido una "falta médica", por cuanto un error podría explicarse de muchas maneras, en especial en el campo de la medicina. En estos casos, fatalmente, la responsabilidad del actor será simplemente moral. Su sanción se produce solamente en la conciencia del propio facultativo $o$, en determinadas ocasiones, cuando el error trasciende, se produce el juicio moral de la conciencia pública, la que así sanciona al médico.

Cuando la "falta médica" cae dentro del ámbito de la responsabilidad legal, la sanción es determinada por los tribunales judiciales, los que siempre tienen en cuenta la índole dolosa o culposa del acto médico. En estos casos, la responsabilidad legal del médico puede ser de carácter civil o penal. Si se trata de una responsabilidad puramente civil, el facultativo está obligado a reparar la falta, indemnizando a la víctima. Si la responsabilidad es penal, toca a la Sociedad sancionar la "falta médica" mediante la aplicación de la pena que corresponda, conforme a las disposiciones del Código Penal, y, a la vez, el establecimiento de la reparación civil en favor de la persona que ha sufrido el daño o de sus herederos. Como lo ha indicado acertadamente el Maestro mexicano José Torres Torija, la responsabilidad penal del médico es la obligación que tiene de reparar faltas cometidas en el ejercicio profesional, indemnizando a la persona dañada, y sufriendo una pena.

El presente trabajo ha de estudiar únicamente la responsabilidad penal del médico, por faltas cometidas en el ejercicio de su profesión. Pero, como se acaba de indicar, no puede hacerse una separación tajante entre la responsabilidad penal y la civil, ya que toda persona responsable penalmente lo es también civilmente, toda vez que es de su obligación reparar los daños causados por el delito. Es sabido que la reparación civil se ha convertido en acción pública en el vigente Código punitivo, constituyendo esta. institución una forma de protección que debe el Estado a la víctima del delito. por lo que la responsabilidad penal y la responsabilidad civil se hallan intimamente ligadas.

Conviene aclarar, igualmente, que este estudio carece de la pretensión de profundizar mayormente este tema tan interesante, por cuanto forzosamente habrá que considerar la tiranía del tiempo y del espacio. Sólo examinará el tema en sus lineamientos generales, interesándose en divul. gar algunos básicos conceptos acerca de la responsabilidad penal del médico-cirujano, nacida de una "falta médica". Pero, eso sí, tratará de ser claro y preciso, cualidades imprescindibles en un trabajo de esta índole.

Hoy nadie duda de que el médico-cirujano tiene la responsabilidad jurídica de los errores que cometa en el ejercicio profesional. Estos errores 
constituyen "faltas médicas". Pero ¿cómo se podría definir lo que es "falta médica"?

Los libros de consulta están llenos de definiciones de lo que es "falta médica", todas ellas muy similares. Por tal motivo bastará dar a conocer la de Oesterlen: "La "falta médica" es el error contra las reglas conocidas por la ciencia que se profesa y la causa lógica del efecto nocivo". No hay duda de que se trata de una excelente definición, bastante precisa.

Sin embargo, conocida la definición surgen nuevas interrogaciones, como éstas: ¿Puede saberse, con exactitud, si las reglas generales reconocidas por la ciencia han sido o no aplicadas? Y ¿cómo determinar si el acto médico fué o no la causa lógica del efecto nocivo? No cabe duda de que es sumamente difícil el determinar fielmente cuándo se ha producido una "falta médica", para hacer posible la responsabilidad del médico-cirujano. Y, por otro lado, no siempre es fócil resolver si el resultado nocivo es o no producto de una "falta médica", para los efectos de la aplicación de la ley punitiva.

Las dificultades se acrecientan al recordar que uno de los más fundamentales principios del Derecho Penal liberal es el que señala que la inocencia siempre se presume y que la inculpación requiere prueba. ¿Cómo probar, entonces, la "falta médica"? ¿Cómo determinar con certeza si se trata o no de un caso fortuito, siempre alegado por el facultativo?

Un autor indica que "a un médico en el desempeño de su labor no se le puede exigir y obligar a tener una habilidad extraordinaria. Solamente podemos pedirle cierto grado de habilidad normal". Estos conceptos han de tenerse presente cuando se desee determinar si un acto médico constituye o no una "falta médica", si se procede con amplio espíritu de justicia. Pero, no cabe duda, que este pensamiento se halla incompleto. Deberá agregarse que al médico-cirujano no puede permitírsele ignorancias o descuidos en el ejercicio profesional, que estos hechos demostrarían una habilidad sub-normal. En estos casos la responsabilidad penal del facultativo sería incuestionable, por cuanto existiría "falta médica". Claras imprevisiones, descuido en el conocimiento de los adelantos de la ciencia médi$c \alpha$, faita de destreza, etc., etc. son hechos reveladores de impericia y, naturalmente, constituyen "faltas médicas", por las que el diplomado deberá responder penalmente. Sin embargo ¿es fácil probar las imprevisiones, el descuido en el conocimiento de los adelantos de la ciencia médica, la falta de destreza, etc.? ¿Bastará la información de peritos, todos ellos colegas del médico que presumiblemente ha cometido "falta médica"?

\section{EVOLUCION DEL CONCEPTO \\ DE LA RESPONSABILIDAD PENAL DEL MEDICO}

La responsabilidad penal de las persomas que viven de la aplicación de métodos curativos existe desde remotas épocas, puesto que ya se hacía efectiva en el antiguo Egipto, en Grecia, en Roma, entre los pueblos bárbaros, etc. Pero el concepto que se ha temido de esta responsabilidad ha ido. variando en el trascurso de los siglos, debido a muy diversas influencias: oscurantismo, prejuicios, sentimientos religiosos, voluntad arbitraria de je- 
fes y monarcas, culturización de las masas, divulgación de los conocimientos científicos, comercialización de la profesión médica, etc.., etc. Por tanto, hoy se tiene un concepto bastante diferente al que predominaba antiguamente.

Por otro lado, el concepto que se ha tenido de lo que es "falta médi$\mathrm{ca}^{\prime \prime}$ ha ido igualmente cambiando en forma paralela al perfeccionamiento de los sistemas de curación. A medida que la medicina fué dejando su empirismo, para hacerse más Ciencia, han nacido nuevas figuras de estimación, cunque siempre más razonables. Puede afirmarse que en la actualidad predomina una concepción más justa de la responsabilidad penal del médico-cirujano, sin que esto quiera decir que ésta haya disminuído.

Al perder el médico mucho de su prestigio taumatúrgico y su cureola de sacrificio y de honestidad indiscutida, la conciencia colectiva se ha mostrado más y más exigente para hacer efectiva la responsabilidad penal del profesional por faltas cometidas en el ejercicio do la medicina. Con el fortalecimiento de su sentido crítico, las mayorías han aprendido a defender su salud y sus vidas en forma más efectiva, dentro de la ley.

Empero, no siempre es posible esta defensa. Sólo a manera de ejemplo se citará un caso patético: un médico llamado a operar un apéndice enfermo, intervino quirúrgicamente en el riñón, alegando que existía necesidad de actuar de inmediato y que era conveniente aprovechar de la operación primeramente señalada. El paciente y su familia se dieron por satisfechos con la explicación del médico-cinjano, debiendo cancelar una subida factura presentada por el médico.

En defensa del enfermo, en algunos países es obligatorio que medie el consentimiento del paciente o de las personas con derecho a prestarlo, zuando el operado esté incapacitado física o legalmente a dario. En los Estados Unidos de Norte Ámérica, por ejemplo, muchos Estados poseen legislaciones que hacen responder civil y penalmente al médico-cirujano que no ajuste sus actos médicos a esta norma. No es raro que se exijan judicialmente fuertes indemnizaciones a los facultativos que violan la regla indicada. No faltan casos de pacientes o familiares de éste que aprovechan de la buena fe de un diplomado con fines de lucro, por lo que los facultativos y las instituciones hospitalarias, públicas y privadas, se han visto obligados a prevenirse de toda suerte de reclamaciones, empleándose una máxima cautela.

Como es racional, los nuevos conceptos que actualmente existen acerca de la responsabilidad penal del médico-cirujano han repercutido en el Derecho. Las legislaciones de los países civilizados no han hecho sino reflejar estos nuevos conceptos predominantes. En nuestro país, el Código Penal sigue la indicada tónica, sancionando las faltas cometidas por un facultativo en el ejercicio de su profesión, esto es, penando las "faltas médicas".

\section{DELITOS QUE NO SE TIPIFICAN COMO "FALTAS MEDICAS"}

Nuestro Código punitivo tipifica una serie de infracciones cometidas por el médico-cirujuno en el ejercicio profesional, considerándolas especí- 
ficamente como "faltas médicas". El Código Penal, pues, conceptúa estos actos infraccionales de manera particular.

Aparentemente, suelen determinarse fácilmente estos actos médicos que constituyen infracciones especialmente tipificadas como "faltas médicas". Pero no siempre sucede así, especialmente cuando $\alpha$ un crimen ordinario se le disfraza como si fuera "falta médica". La obligación penal nacida de este acto delictuoso rebasa a la que provoca un acto médico erróneamente cumplido. Naturalmente, su sanción habrá de ser dlistinta. Para comprenderse mejor lo dicho, será útil recordar un ejemplo dado por el Profesor Luis Jiménez de Asúa.

En 1947, el Maestro español Jiménez de Asúa dictó un cursillo de Seminario de Derecho Penal en la Facultad de Derecho de la Universidad Nacional Mayor de San Marcos de Lima, cuyas enseñanzas aún perduran. Entre los numerosos casos propuestos en este cursillo, figuró el siguiente: El Dr. Pérez, médico de un pequeño pueblo, recibe en consulta al Sr. Rodríguez, antiguo compañero de la infancia con quien tuvo serias reyertas que al facultativo le dejaron muy profundo rencor. Al ver nuevamente al antiguo enemigo renacen sus odios y al comprobar, por reconocimiento médico, que su ex-condiscípulo necesita una seria intervención quirúrgica de urgencia, concibe la idea de darle muerte en la operación, puesto que de tal modo nadie tendrá sospecha de la causa del fallecimiento. Poco después comienza la intervención quirúrgica, que se ve obligado a verificar solo, con una simple enfermera, pues en el lugar no existe otro facultativo. Pone a contribución todas las reglas del arte, pero después de seccionar una arteria, cuyo corte, en efecto, era indispensable, en vez de ligarla, deja que el paciente se desangre. Así muere el Sr. Rodríguez en el curso de la operación.

Expuesto el caso, preguntaba Jiménez de Āsúa: ¿Se trata de una "falta médica"?. ¿Habrá que aplicar o no el precepto legal que tipifica una "falta médica"?. ¿La muerte del paciente se ha debido a negligencia del médico-cirujano o se trata de un homicidio cometido con perfidia?. ¿Existe fortuitidad en el acto médico? ¿Existe o no responsabilidad penal para el médico-cirujano que realizó la intervención? ¿Será de aplicación el artículo 152 del Código Fenal, que tipifica el homicidio cometido con perfidia, o el 156, que tipifica el delito resultante de una "falta médica"?.

El Código punitivo peruano tipifica los delitos resultantes de "falta médica" y determina una sanción específicamente diferente para ellos. Pero en el caso propuesto, el Dr. Pérez se aprovechó de un acto médico para asesinar a su antiguo enemigo, por lo que no puede clasificarse el delito cometido como "falta médica". Se trata de un delito absolutamente ajeno al ejercicio profesional, no obstante que se haya aparentado fortuitidad o negligencia. Se ha cometido un homicidio cuyo móvil fué la venganza. Por tanto, no es de aplicación el artículo 156 del Código Penal, sino el 152.

\section{EL CASO FORTUITO}

Los estudiantes de Derecho Penal aprenden, desde las primeras lecciones, de que no existen sino dos especies de culpabilidad: el dolo y la 
culpa. Consiguientemente, el médico-cirujano no será responsable penalmente por sus actos profesionales si el acontecimiento dañoso que ha resultado de su acción u omisión no fué querido, ni previsto y se tomaron todas las necesarias precauciones para que no se produjeran los efectos perjudiciales para el paciente. El médico ha cumplido un deber profesional, sin que pudiera exigírsele otra conducta, ya que actuó correctamente. Se trata. incuestionablemente, de un caso absolutamente fortuito y no es posible, entonces, responsabilizar penalmente al facultativo, toda vez que el daño se produjo no obstante las precauciones que previamente se tomaron. No habiéndose hecho presente el dolo o la culpa en el acto médico, mal pue. de responsabilizarse al médico-cirujano penalmente por los resultados da. ñosos de su intervención.

Está exento de pena "el que practica un acto permitido por la ley o el que procede en cumplimiento de sus deberes de función o de profesión". establece el inciso 4 del artículo 85 del Código Penal. Aunque los resultados del acto médico hayan sido dañosos para el paciente, no existe responsabilidad penal, ya que se efectuó en el cumplimiento de los deberes propios del médico-cirujano, sin intervenir dolo o culpa de parte del facultalivo.

Cuando el acto es médico, debe considerarse la manera en que éste se ha efectuado, en especial. Los resultados nocivos de la acción o de la omisión importan menos. Si se ha ejecutado con la prudencia y la prolijidad debidas no puede existir "falta médica". Como las consecuencias del acto fueron imprevisibles, mal puede existir responsabilidad penal para el médico-cirujano: se ha producido un caso absolutamente fortuito.

El facultativo practicó un acto propio de su profesión, tomando todas las precauciones a fin de evitar cualquier efecto dañoso, ciñéndose a las reglas indicadas por la ciencia de curar, ejecutándolo con la mayor diligencia, pero, no obstante esto, el accidente se produjo. No puede ser imputado el daño a dolo o culpa del médico. Entonces, existió un caso fortuito Y. por tanto, el profesional se halla exento de responsabilidad criminal.

El médico que causa un daño por puro accidente en ocasión de ejecutar un acto profesional, no comete delito, por cuanto están cusentes el dolo y la culpa. Mal puede, por tanto, responsabilizarse penalmente al facultativo. ya que se ha producido un caso fortuito.

\section{"FALTAS MEDICAS" DELICTUOSAS}

Las "faltas médicas" delictuosas se hallan tipificadas por los artículos 156, 162, 168, 363 y 367 del Código Penal. A continuación, se haró un breve comentario de cada una de estas "faltas médicas" por las que son responsables penalmente los médicos-cirujanos.

Homicidio por negligencia (Art 156 del C P ).-."El que por negligencia, causare la muerte de una persona, será reprimido con prisión no mayor de dos años". "La pena será prisión no menor de un mes ni mayor de cinco años, si, por negligencia, el delincuente hubiere infringido un deber de su función, de su profesión o de su industria".

El médico-cirujano puede causar la muerte de uno de sus pacientes. 
en el ejercicio de su profesión por negligencia. Ausente el factor de la intencionalidad, se habría cometido un delito culposo.

Es punible por cuanto taxativamente lo establece asi la ley, de conformidad a lo dispuesto por el artículo 82 del Código punitivo: "El agente de infracción no intencional es punible en los casos taxativamente establecidos por la ley, cuando el daño o el peligro es ocasionado por negligencia". "Comete delito por negligencia, el que, por una imprevisión culpable, obra sin darse cuenta $o$ sin tener en cuenta las consecuencias de su acto. La imprevisión es culpable, cuando el autor del acto no ha hecho uso de las precauciones impuestas por las circunstancias y por su situación personal".

Los precedentes legislativos de este artículo se encuentran en los códigos penales de Argentina, Francia, Bélgica, Brasil, etc. Se halla inspirado en el artículo 84 del Código Penal argentino, que reprime con prisión de seis meses a dos años e inhabilitación especial en su caso, por cinco a diez años, al que por imprudencia, negligencia, impericia en su arte o profesión o inobservancia de los reglamentos ó de los deberes de su cargo. causare a otro la muerte. Es incuestionable que la disposición del Código Penal argentino es más completa.

Es sabido de que la culpa siempre se la concibe por tres de sus principales elementos: la imprudencia, la negligencia y la impericia. La imprudencia supone emprender actos inusitados, fuera de lo común, y que. por ello, pueden causar efectos dañosos. La negligencia consiste en no tomar las debidas precauciones al cumplirse con actos, ya sean ordinarios o excepcionales. Y la impericia consiste en ejecutar alguna actividad profesional no conocida correctamente por el agente, esto es, cuando existe falta de conocimientos y de aptitud para la realización de determinados actos. Como es de verse, estos elementos no pueden confundirse, toda vez que sus características son diferentes. El Código Penal peruano parece que los engloba a todos al decir -específicamente tratándose de una "falta médica"- - "si, por negligencia, el delincuente hubiera infringido un deber de su profesión".

Es correcta la posición del Código peruano, toda vez que los más notables penalistas basan la culpa en la "conducta contraria al deber'. Como indica Jiménez de Asúa: "Siempre, al ejercer una profesión, oficio o función cualquiera, existe un deber exigible". Justamente, cuando no se actúa de acuerdo con este deber exigible, hay delito culposo.

El elemento esencial de la culpa es la falta de previsibilidad, es decir, si el agente no ha cumplido con su deber de prever lo previsible. Por ejemplo: un médico-cirujano opera a un paciente empleando un método novísimo, aún no experimentado por el propio facultativo, por lo que se halla expuesto a causar efectos dañosos sobre el enfermo. Ha actuado el cirujano con manifiesta impradencia, faltando, por tanto, $\alpha$ un deber profesional, al no prever lo que era previsible. Si el paciente muere, se ha cometido el delito tipificado por el artículo 156 del Código Penal, ya que comportan responsabilidad penal, aunque atenuada, las acciones $u$ omisiones derivadas de la imprudencia, negligencia, impericia o violación de los reglamentos o deberes de cargo. 
La infracción de un deber profesional debiera traer aparejada igualmente la sanción específica de la suspensión del derecho de ejercer la medicina por tiempo más o menos largo, impuesta como sanción accesoria de la que la ley represiva trae como principal, toda vez que el facultativo que ha incumplido un deber exigible no merece continuar ejerciendo su. profesión, cuya práctica debe serle suspendida. Incuestionablemente, la disposición peruana debió considerar esta inhabilitación especial.

Aborto (Art. 162 del C. P.).-"Los médicos, cirujanos, parteras, farmacéuticos y cualesquiera otras personas dedicadas a profesiones sanitarias. que abusaren de su arte para causar el aborto, sufrirán la pena de los artículos anteriores (159, 160 y 161) e inhabilitación especial por un tiempo. no menor de cinco años".

No faltan autores que sostienen que el aborto debe quedar enteramente en el ámbito individual, ya que, estiman, no interesa a la comunidad. Este concepto hace tiempo que ha sido ampliamente superado. Por. ejemplo, la misma Rusia Soviética ha prohibido y castigado las prácticas abortivas desde hace muchos años atrás. Sólo acepta que se le ejercite en. los casos en que la continuación del embarazo represente un peligro para la vida o salud de la mujer encinta $y$, en tales supuestos, únicamente podrá practicarse en los hospitales $\mathrm{Y}$ maternidades, penándose a los culpables, aunque intervenga un médico, si se verifica en otros lugares. Solamente acepta, pues, el aborto terapéutico.

El Código Penal peruano sigue la misma tendencia del código soviético, aunque en forma menos extricta. El artículo 162 del Código peruano se refiere a "abuso profesional", el que significa que se emplea el título de médico-cirujano para cometer, a su amparo, el delito de aborto. Si el profesional, prevaliéndose de su título, lo aprovecha para cometer este delito, su responsabilidad social $Y$ penal no puede ser discutida.

En la actualidad, todos los pueblos civilizados penan el delito de aborto, salvo casos muy particulares. Dede estimarse que existe aborto cuando el producto de la concepción - sea en estado de embrión o de feto- es expulsado antes de que el útero lo haga naturalmente. Como es lógico, no se sanciona el aborto que se produce por causas no deseadas, tales como por anormalidad patológica o por accidente, ya que se trata de un aborto espontóneo, impropiamente llamado fisiológico por algunos autores.

Nuestra legislación penal no acepta el aborto eugenésico, ni el aborto debido a causas sociales, que es aquél en que la mujer embarazada ha sufrido violencia carnal que la dejó en cinta o casos similares conocidos. bajo el denominativo de "legítimo", etc., etc. Solamente admite el terapéutico, mejor denominado necesario. El artículo 163 del Código Penal peruano determina que "no es reprimible el aborto practicado por un médico con consentimiento de la mujer en cinta, si no hubiere otro medio de salvar la vida de la madre o de evitar en su salud un mal grave y permanente".

Podría aplicarse a lo que nuestra legislación penal entiende por aborto criminal la definición dada por José Agustín Martínez, clara y sencilla: "Aborto criminal es la interrupción intencional del proceso normal 
reproductivo de la especie, causada o provocada por la expulsión o destrucción de la concepción, practicada con infracción de las leyes penales".

Puede acontecer que sobrevenga la muerte de la grávida, lo que constituye un riesgo siempre presente, al igual que hemorragias, infecciones, etc. El autor tiene la plena responsabilidad de este evento, por cuanto no sólo era posible, sino probable. Suponiéndose que el médico no tuvo la intención de causar la muerte de la mujer en cinta, ¿qué delito se. ha cometido?. Si se tratara de un aborto terapéutico, habría homicidio culposo, por haberse hecho presente la negligencia del facultativo. Pero si se. trata de alguna otra de las formas de aborto (eugenésico, legítimo, etc., etc.) el delito deberá considerarse como un homicidio ordinario. Además. sería del todo necesario determinarse si se emplearon los medios consen: tidos por la grávida u otros distintos.

Sin embargo, muchos autores sostienen que en estos casos aparece la figura jurídica del delito preterintencional, por cuanto se ha originado un mal mayor al esperado. Se ha producido un dolo más allá de la intención del agente. Otras penalidades juzgan -como lo piensa José Águstín Martínez- que "no puede hablarse de preterintencionalidad en este evento de la muerte consiguiente de la grávida por la estrecha concatenación del evento con el acto doloso del procurado aborto. Ni el consentimiento ni. aún la instancia de la grávida pueden servir de excusa ni atenuación alguna al agente".

El abuso profesional conlleva la sanción específica de la suspensión del derecho a ejercer la protesión de médico-cirujano por el tiempo que señala el artículo 162 del Código Penal, lo que es justo. En los casos de múltiple reincidencia o de habitualidad debiera imponerse la cancelación definitiva del título académico, lo que no acepta nuestra legislación penal. equivocadamente.

Lesión corporal, por negligencia (Art. 168 del C. P.).-_"El que por negligencia causare una lesión corporal, será, por querella de parte, repri: mido con prisión no mayor de dos años o multa de la renta de tres a noventa días". "El juzgamiento será de oficio y la pena de prisión no mayor de tres años, si la lesión fuere grave, o si, por negligencia, el delincuente hubiere infringido un deber impuesto por su función, su profesión o su. industria". "El juez podrá acumular la multa con la prisión".

Al comentar esta "falta médica" delictuosa no habrá sino que repetir lo que ya se ha dicho con relación a lo que dispone el artículo 156 del Código Penal, ahora referida a una lesión corporal.

Violación del secreto profesional (Art. 363 del C. P.)._- "El que te-niendo noticia, por razón de su estado, oficio, empleo, profesión o arte, de: secretos cuya publicación pudieren causar daño, los revelare sin consentimiento del interesado o sin que la revelación fuere necesaria para salvaguardar un interés superior, será reprimido, por acción del perjudicado, con prisión no mayor de dos años o multa de la renta de tres a noventa días e inhabilitación, conforme a los incisos 1 y 3 del artículo 27, por no más de tres años". "Están especialmente comprendidos en esta disposición los eclesiásticos, abogados, apoderados, notarios, médicos, farmacéuticos, los cuxiliares de estas personas y las parteras". "También están especialmen" 
te comprendidos los estudiantes de medicina que conocieran algún secreto con ocasión de sus estudios".

Es un principio universalmente aceptado el del secreto profesional, toda vez que su violación podría ocasionar serios perjuicios al propio cliente, a sus familiares o a terceros. Su violación naturalmente es sancionada. Naturalmente, no habrá revelación punible cuando se dan a conocer estos secretos para cumplir un deber moral o jurídico, de valor o finalidad notoriamente superiores al mantenimiento del secreto 0 de los secretos o para cumplir con un mandato, ruego o encargo contenido en el que fué confiado $y$ se revelare exclusivamente a las personas que correspondiere.

De todos los profesionales, los que se encuentran en mejores condiciones de conocer los secretos más íntimos de sus clientes son los médicocirujanos, no solamente de aquellos que se refieren a las enfermedades que aquejan al cliente, sino que, además, de otros muchos de extremada delicadeza y que al cliente conviene permanezcan en estricto secreto. No debe extrañar, por tanto, que nuestra legislación penal sancione la vioiación de secretos conocidos por el médico en el ejercicio profesional, si son divulgados sin el consentimiento del interesado o que lo sean sin que existan motivos especiales para darlos a conocer a personas determinadas.

Es deber del médico, pues, quardar el secreto que se le confía en el ejercicio profesional o que lo conoce al ejercerla. Podrá revelarlo únicamente con el consentimiento del interesado o cuando asi lo exige un deber jurídico. Pero hay casos en que el médico está obligado a revelar o a denunciar ciertos hechos, aunque no sea éste el deseo del cliente, como en los casos de enfermedades contagiosas que pongan en peligro la salud pública, indicios de muerte violenta, etc. En estos casos existe un interés superior que debe predominar: el interés público. siempre más importante que el interés personal o de grupo. Es, sin duda, el más valioso que existe. Este es el motivo que obliga al médico a denunciar determinados hechos, conocidos justamente en el ejercicio de su profesión.

La violación del secreto profesional no solamente es sancionada con prisión o multa, sino que igualmente con la pena de inhabilitación, toda vez que quien viola un secreto profesional no es digno de ejercer su ministerio. De acuerdo a ley, el médico que no sabe guardar un secreto profesional es suspendido en el ejercicio del arte de curar.

Expedición de un certificado falso (Ärt. 367 del C. P.).- "El médico que maliciosamente expidiere un certificado falso concerniente a la existencia o no existencia, presente o pasada, de enfermedades físicas, será reprimido con prisión no mayor de un año y multa de la renta de tres a noventa días, sin perjuicio de la inhabilitación por otro tanto de la condena, conforme al inciso sexto del artículo 27". "Si se hubiese dado la falsa certificación con el objeto de que se admita o se detenga a alguien en un hospital de dementes, la pena de prisión podrá ser hasta cinco años, sin perjuicio de una multa de la renta de treinta a noventa días y de la misma inhabilitación". "Se impondrá, en su caso, las mismas penas al que intencionalmente hiciere uso de una certificación falsa, como si el contenido fuera exacto".

¿Qué se entiende por "certificado médico"? Es el documento que ex- 
tiende un diplomado en medicina, después de examinar psicofísicamente a una persona $y$, en su caso, estudiar los análisis que fueren necesarios, dando a conocer la existencia o inexistencia, presente o pasada, de alguna enfermedad física o psíquica sufrida por el sujeto al que se refiere el certificado, expedido a solicitud de éste, de sus familiares, de los jueces o de otras autoridades competentes.

La expedición de estos certificados se hacen necesarios en múltiples casos: determinando que una persona sufre de una enfermedad venérea - la ha sufrido y que, por tanto, puede haber causado una infección en el comercio sexual a ntra persona; señalando la necesidad de que un enfermo sea internado o no en un hospital o establecimiento sanitario; justificando la inasistencia a una audiencia judicial por causa de enfermedad; etc.; etc.

La responsabilidad penal del médico que extiende un certificado en que maliciosamente se adultere la verdad es obvia, por cuanto no solamente se afianza algo inexacto, sino que mediante esta falsedad puede causarse serios perjuicios a la persona a quien el certificado médico se refiere o a terceras personas. Es incuestionable, pues, que comete una grave infracción el médico que certifica falsamente la existencia o la inexis. tencia, presente o pasada, de una enfermedad, a sabiendas de la inexactitud de su dicho. El artículo 367 del Código Penal tipifica este delito.

Al expedir un certificado falso, el médico se hace indigno de la confianza que se ha depositado en él. Es justo, entonces, que esta infracción traiga aparejada igualmente la sanción accesoria de la suspensión del ejercicio profesional.

\section{LAGUNAS DEL CODIGO PENAL}

Se ha visto que el Código punitivo peruano tipifica algunos de los delitos que resultan de "faltas médicas". Es incuestionable, sin embargo, que en este cuerpo de leyes han sido omitidas muchas faltas médicas que debieran ser sancionadas penalmente.

El rigor extremo de un Código Penal constituye un serio inconveniente para lograr una justicia humanizada. Tampoco deben tipificarse como delitos muchos actos que la conciencia pública está lejos de considerarlos como infracciones, especialmente cuando se traten de actos médicos, dada la naturaleza particular que tiene toda "falta médica". Además, debe destacarse que es prácticamente imposible abarcar todos los casos de faltas médicas sancionables, justamente debido a las características suigéneris de toda "falta médica". Esta es la razón de que a continuación sólo se enumerarón algunas de estas omisiones del Código Penal vigente.

Negar o rehuir la prestación de servicios profesionales.-El Código Penal de 1863, anterior al vigente, contaba con un artículo -el 165- que penaba a los médicos o cirujanos que, sin justa causa, rehusasen, en circunstancias urgentes, prestar servicios de su profesión o concurrieran fuera de tiempo o abandonasen a un paciente sin motivo grave. Este delito no ha sido considerado por el vigente, cometiéndose una seria omisión.

No es infrecuente que un médico-cirujano rehuse el prestar sus 
servicios profesionales a un enfermo, aún en circunstancias de suma urgencia, o que concurran con gran atraso a la casa del paciente o al nosocomio en donde éste se halla internado. Naturalmente, estos malos facultativos se valen de múltiples razones para explicar su actitud, peligrosa para la salud y la vida del enfermo. Se alega que se está ausente en el momento en que se le llama o que alguna dolencia le impide concurrir al lado del paciente. Estas son las explicaciones más corrientes, sin que falten otras muchas y diversas, distintas según la ocasión. Demuestran. así, una ausencia absoluta de ética profesional y olvidan el brillante pensamiento de Kufeland: "Cuando tu enfermo esté en peligro, arriesga todo para salvarlo, aún tu reputación".

En los últimos tiempos se han producido algunos casos que se podrían calificar como monstruosos. Por ejemplo, algunos médicos han negado rotundamente su concurso ante solicitudes desesperadas de los familiares de enfermos graves, solamente porque éstos se hallaban internados en nosocomios atendidos por otros colegas afiliados a otras asociaciones gremiales, exigiéndose autorización escrita de las autoridades de la institución gremial a la que estaban afiliados. Posponían deberes sagrados de función frente a cuestiones secundarias de registros de grupos. Es así como por cuestiones principistas, de intereses o por simples rivalidades profesionales, se perdían preciosos momentos para salvar a un enfermo grave.

Al rehusarse a cumplir con un irrefragable deber profesional, el cual consiste en atender a los enfermos que requieran de sus servicios con urgencia, se comete no solamente un gravísimo yerro, sino también una seria "falta médica", la que debe ser penada, en la forma que lo hacía el Código Penal de 1863. Y, en todo caso, por lo menos estos facultativos deben probar fehacientemente las graves razones que tuvieron para no atender a un enfermo $y$ que lo han impedido cumplir con su deber, razones que deberán ser sopesadas cuidadosamente, para determinar si las disculpas son atendibles o no $y$ resolver con integridad $y$ justicia. Si no existieran graves razones que vengan a explicar la actitud del facultativo, es lógico que éstos reciban una sanción, ya que al negarse a cumplir con sus deberes de función están poniendo en peligro la salud y la vida de las personas que requieren de sus servicios profesionales.

Aplicación de los denominados "sueros de la verdad".-Aunque en forma excepcional, algunos médicos han aplicado los llamados "sueros de la verdad" $\alpha$ inculpados, en la etapa policial de la investigación criminal. ¿Puede ser permitida esta aplicación en los campos policial o judicial?. O. como se pregunta el notable penalista Manuel López-Rey: ¿Hasta qué punto es lícito o legal provocar una perturbación psíquica para obtener una verdad, en el supuesto de lo que se dice sea realmente verdadero?. Si la Ley peruana prohibe - tanto en el proceso policial como en el judicial- el empleo de la violencia, de la intimidación, la coacción, las promesas, las dádivas, etc., en general, ¿podrá aceptarse que se emplee procedimientos que atentan contra la personalidad humana, como es la aplicación de los "sueros de la verdad". ¿No se produce una desconsideración jurídica de la persona y de la personalidad humana, inaceptable por la Ley peruana?. ¿Puede acertarse la espontaneidad de una manifestación lo- 
grada mediante la aplicación de los referidos sueros, aunque medie la aceptación del inculpado?.

El empleo de estos sueros coloca al médico que los aplica en situación poco envidiable, incuestionablemente ilegal. Con su intervención se pone al imputado en un estado de desvalimiento, permitiéndose, así, que éste traicione sus deseos más profundos y ponga en manifiesto sentimientos, ambiciones, anhelos, etc. que nadie tiene el derecho de conocer, cuando se trata de una investigación policial o judicial, absolutamente distinta al tratamiento médico propiamente dicho. La legislación peruana se funda en el respeto de la persona humana $y$, por tanto, no puede tolerar un ataque a la personalidad del individuo. Por consiguiente, un médico que se preste a aplicar los denominados "sueros de la verdad" en procedimientos policiales o judiciales está violando el espíritu de estas disposiciones legales $\mathrm{y}$ debe, incuestionablemente, ser sancionado.

Mucho se ha hablado y escrito acerca de lo que acontece en Rusia Soviética $y$ en otros países totalitarios, en donde se utilizan estos métodos con finalidades políticas. ¿Es posible permitir su empleo en países más o menos democráticos, aunque sea para fines no políticos?. En el Perú debe penarse a quienes lo emplean en el órea procesal penal, ya sea en la práctica policial o en la judicial, especialmente si se trata de un médico. el que jamás debe prestarse a utilizar los llamados "sueros de la verdad" en estos campos.

Su aplicación debe ser consentida solamente en el terreno médico, para el mejor tratamiento de ciertos enfermos mentales, sean o no delincuentes, por cuanto para lograrse un mejor tratamiento o una curación de algunos psicopáticos la Ciencia acepta el uso de estos sueros. En el campo psiquiátrico se acepta ampliamente su aplicación, pero en el proceso penal no puede ser consentida en el Perú. No solamente porque su applicación constituye la negación de derechos sagrados de la personalidad humana, sino porque, además, sus resultados son frágiles. Según estudios reclizados por V. Lorenz, se ha llegado a la conclusión de que los "sueros de la verdad" no significan la obtención de la verdad, sino de una información en la que tanto pueden aparecer hechos ciertos, junto con manifestaciones de dezeos, aspiraciones, sentimientos más o menos ocultos, circunstancias imaginadas, fantásticas y desfiguradas, etc., etc. Las manifestaciones hechas bajo los efectos de los mal llamados "sueros de la verdad" muchas veces son inseguras y alejadas de la realidad.

No es posible aceptar el ejemplo de los Estados Unidos de Norte América en donde un gran sector de la práctica policial y judicial admite la aplicación de los "sueros de la verdad", seguramente inspirada por gastado concepto del tecnicismo. En Inglaterra no ha progresado mayormente la implantación de este método en estos campos. Y en Francia siempre ha merecido una franca repulsa. En los países latinoamericanos no se acepta este procedimiento ni en lo policial ni en lo judicial, tal cual acontece en. el Perú. Sin embargo, no han faltado casos en que se le ha aplicado ilegaimente. Justamente, para impedir se repitan estos casos es que se debe sancionar al médico que aplique los referidos sueros en estos campos. En nuestro país, en donde predominan los principios del Derecho Penal libe- 
ral, esta práctica debe estar absolutamente prohibida $\mathrm{y}$ ningún médico debe prestarse a emplearla antes de la sentencia judicial, bajo sanción si falta a este deber.

Otras Omisiones:-Como se ha expresado, las "faltas médicas" siempre presentan particulares características, por lo que es tarea bastante delicada señalar, con espíritu de justicia, aquéllas que debieran ser sancionables penalmente. Frácticamente es imposible, pues, puntualizar todas las omisiones que en este terreno se anotan en el vigente Código Penal, por las razones antes indicadas.

Al registrarse en este trabajo los ejemplos anteriores sólo se ha intentado poner de relieve que se comprueban lagunas en este cuerpo de leyes. Es indudable que se presentan otras muchas omisiones, toda vez que es incuestionable que no se han considerado todas las "faltas médicas" que debieran constituir infracciones penadas por la Ley. Las aludidas en los capítulos precedentes son meros ejemplos de algunas de estas "faltas médicas".

\section{SERIAS DIFICULTADES PARA RESPONSABILIZAR PENALMENTE AL MEDICO-CIRUJANO}

No cabe la menor duda de que es del todo necesario resguardar al médico-cirujano de resentimientos, venganzas, pasiones y hasta de chantajes de parte de enfermos o familiares de éstos que no concuerdan con los resultados de la intervención del facultativo. Pero igualmente todos están de acuerdo en que debe protegerse a las personas que sean víctimas de las faltas graves que el profesional pueda cometer en el ejercicio de su ministerio. Pero no siempre ešto es fácil, por cuanto siempre es dificulto-

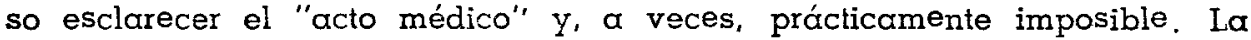
apreciación y compulsa de muchos elementos de convicción generalmente constituye un proceso complicado $\mathrm{y}$, dada su tecnicidad, solamente otros profesionales estón en aptitudes de realizar esta tarea. Los jueces, al apreciar estos elementos, se han de enfrentar a una serie de factores ajenos al conocimiento legal, desconocidos para el que no es médico-cirujano. Forzosamente han de fiar en la información que les presten otros colegas de] profesional acusado, entre los cuales predominan un exceso de compañerismo, lo que produce lo que se conoce con el nombre de "conspiración de silencio". Consecuencia lógica de lo dicho es que, muchas veces, esta clase de delitos quedan impunes.

Los jueces han de llegar a una conclusión basándose en el informe de otros médicos. Y aunque la parte puede constituirse en "parte civil" para reclamar los daños y perjuicios producidos, interviniendo, por tanto, en el proceso penal, siempre es de suma dificultad probar la "falta médi$\mathrm{ca}^{\prime \prime}$ sancionable, salvo que otro facultativo informe con entera imparciali. dad $\mathrm{y}$ se enfrente a la opinión de otros colegas, lo que no siempre es factible. 
R. Garraud ha escrito: "Las personas que ejercen legalmente el arte de curar están sujetos a la responsabilidad penal por homicidio o lesiones involuntarias cuando la impericia es causa de éllas. La cuestión jamás fué dudosa para nadie en teoría, pero es sumamente delicada en la práctica, en razón de la dificultad de apreciar los temas jurídicos y científicos que se promueven en cada caso. Sin duda los Tribunales no se reconocen en el derecho de condenar a personas que ejercen legalmente el arte de curar, si éstas han aplicado simplemente al enfermo las teorías, las opiniones y los sistemas médicos, aunque no falten controversias entre ellos. Los Tribunales no pueden apreciar la oportunidad, ni la ejecución, más o menos perfecta, de un tratamiento médico o de una operación quirúrgica". Irónicamente concluye: "Desde este punto de vista, se puede matar sin consecuencias". Sin embargo, agrega que todo cambia cuando el médico contraviene las reglas generales del buen sentido y de la prudencia a que debe conformarse en el ejercicio de sus funciones. Pero, agregamos, ¿puede determinarse siempre cuando el médico ha contravenido las reglas generales del buen sentido y de la prudencia? Indudablemente se trata de una ardua tarea.

Si una persona en el ejercicio profesional trata médicamente $\alpha$ un paciente: ¿Puede graduarse la oportunidad de una intervención determinada? Y ¿cómo podrón apreciar acertadamente los Tribunales -integrados por hombres de leyes- si un tratamiento curativo o una operación quirúrgica eran los indicados por la Ciencia a un caso determinado? En verdad, frente al problema de la responsabilidad penal del médico-cirujano se alzan innumerables interrogaciones de contestación más que difícil. Dada su complejidad, es casi imposible determinar con criterio de justicia la responsabilidad penal del médico en muchos de los actos cumplidos en el ejercicio profesional:

Además, hay que tener en cuenta que la Medicina aún se halla en plena evolución y que los misterios del cuerpo humano todavía no han sido esclarecidos. Flaminio Favero expone una serie de conceptos de sumo interés, concordando ampliamente con lo indicado, en una conferencia intitulada "Faltas de los Médicos", la que a veces se encuentra teñida de un espiritual humorismo. Concluye afirmando que la Medicina y el médico son un riesgo específico para el doliente $\mathrm{y}$ que, por tanto, la falta médica siempre existe, constituyendo una realidad inevitable por la naturaleza particular del medio en que actúan: el cuerpo humano.

Claro está que en algunos casos es relativamente sencillo el determinar la responsabilidad penal del médico: aborto, revelación de secretos profesionales, expedición de certificados falsos, etc. y aún no siempre tan fácilmente como acontece, por ejemplo, cuando un médico extiende un certificado, a algún abogado a quien le conviene no asistir a una audiencia judicial. Pero en la generalidad de las veces se plantean tales situaciones que se hace muy difícil responsabilizar penalmente a estos profesionales. Porque siempre deben los jueces preguntarse: ¿cuándo hubo "falta médica"?; ¿cuándo hubo liviandad, engaño o negligencia profesional?; ¿cuándo el efecto nocivo ha sido causado por el propio acto médico, $\sin$ intervención de otros factores extraños? 
Por otro lado, los Tribunales han de tener presente un hecho importantísimo: el facultativo que recién recibe su título ha de corender los secretos de la profesión a costa de práctica y experiencia y está no se adquiere sino se ejercita el arte de curar. Si se alcanza reputación es a fuerza de intervenir en el tratamiento de miles de pacientes, en muchos casos cometiendo errores en el diagnóstico, fatalmente. ¿Son penalmente responsables los médicos que así actúan? Finalmente no puede olvidarse que el médico no trata enfermedades, sino enfermos, cada uno diferente a otro. Lo que puede ser lo correcto para uno, puede ser fatal para otro paciente, ya que la Medicina siempre tiene mucho de conjeturas, toda vez que se trata de una ciencia en contínua evolución. El médico frente a un hecho concreto ha de pensar que éste nunca se halla absolutamente limitado y que las enfermedades varían sus síntomas de acuerdo a un sin número de factores orgánicos. ¿Quién puede ser juez en lo que se relaciona a un diagnóstico y a una terapéutica, sino el mismo médico? ¿Cónro podría señalarse. entonces, cuándo el médico ha cometido una equivocación punible?

Frente a un enfermo los facultativos suelen pensar en forma distinta, de acuerdo generalmente con la especialidad que profesan. Asi un cirujano juzgará que una dolencia habrá de ser curada por medio de una intervención quirúrgica; pero el clínico creerá que debe ser tratada por vía terapéutica $y$ de esta suerte cada especialista. El psiquiatra, el ginecólogo, etc., llegarán, quizás, a otras conclusiones. ¿Puede criticarse esta disparidad de opiniones? Naturalmente que no, por cuanto, al igual que en otras profesiones, la división social del trabajo ha dado lugar a múltiples especializaciones médicas. Lo único que es posible exigirse es que si se comete un error $y$ éste es conocido, sea rectificado de inmediato, antes que se produzca daño al paciente.

Bien ha afirmado Nerio Rojas: "En medicina, la exceoción puede tener tanto valor como la regla. En la práctica clínica, el médico se guía sobre todo por los hechos habituales, pero sin descartar las posibles rarezas". Sin embargo, estas excepciones difícilmente pueden ser conocidas o adivinadas. No puede exigirse a todos los médicos aptitudes sobrenaturales en el ejercicio de su profesión, sin que esto signifique excusarlos cuando demuestren desconocimiento de los casos regulares, pues entonces cometen grave "falta médica".

Hay que reconocer que siempre es problemático el conocer qué sintomas predominan sobre los otros, qué tratamiento deberá seguirse y qué sistema habrá de aplicarse en cada caso particular. Y es natural que así sea, ya que, como señala Paul Guerin: "La independencia del espíritu es el rasgo dominante en la formación del médico. Es lo que ha hecho posible la evolución de la ciencia médica. Lo cierto de hoy es a menudo lo falso de mañana, y frecuentemente el dogma científico, ayer triunfante, es derrocado hoy". Seguramente en ninguna otra profesión es más necesaria la libertad relativa de opiniones.

No hay duda, pues, que se presentan siempre serias dificultades para responsabilizar penalmente al médico-cirujano $y$ para aplicar, con justicia, las disposiciones legales. Se trata de problemas de suma complejidad, la que se ahonda aún más cuando intervienen los factores negativos na- 
cidos de la llamada "conspiración de silencio", la que, incuestionablemente, acusa una notable falta de ética, la que ha de estar por encima de un compañerismo mal entendido, siempre.

¡Qué arduo y penoso se hace el trabajo del juez cuando debe resolver uno de estos casos, siempre embarazosos, delicados $y$ complicados!. 